supposed that the single-phase system is untried. There are in Europe more than thirty different railways, portions of which are now in operation or under construction by single-phase current, aggregating in all more than $85^{\circ}$ miles, while in America there are nearly 1000 miles of railways being so operated. Some of these, however, are not heavy electric railways, but interurban electric railways laid down for electric working from the start. Hence before long it should be possible to obtain ample experience of the results of single-phase working. Some of these systems are of considerable length. Thus the Prussian State Railway will have II2 miles electrically worked, while the Berlin Stadt and Ring Railway will have 366 miles, and in America the Spokane Inland Railway Company has in 5 miles.

\section{Choice of System.}

Many engineers and railway men have unfortunately adopted an attitude of partisanship on this, a question which should be considered primarily on its merits in each particular case. It is quite absurd to generalise and say that the single-phase or the direct-current system is the better. Each has its own field, eacl is excellent and desirable under its own set of conditions, and only those who have studied all the conditions in each particular case can say which is the best scheme to adopt financially.

As regards main-line working pure and simple, engineers have not yet decided quite as to the best systems of doing it, neither are railway men entirely satisfied as to the financial advisability of converting main-line working; but for heavy working under special conditions electrification is being more and more considered. Thus the Grand Trunk Railway has recently equipped the St. Clair Tunnel for electric working, an installation which is notable as being the heaviest railway service in the world handled by electricity. Trains weighing rooo tons are hauled from one end of the tunnel to the other, about two miles, at a minimum speed of ten miles per hour on a gradient of in 5o. The new tunnels under the Hudson River at New York, by which the Pennsylvania Company will obtain access to Manhattan Island itself, are also being electrically equipped for the haulage of main-line Pennsylvania trains, which are naturally of great weight. A project of a somewhat similar character is that which the Great Northern Railroad of America is considering in connection with the electrification of a new section of line over the Rockies, where the three-phase system, which has been a good deal used in Italy and Switzerland, is likely to be adopted.

Thus it will be seen that there is plenty being done in electrification work. It is to be regretted, however, that actual financial results, especially operating costs, have been very sparingly published. While it is known that the North-Eastern Railway Company, for instance, has been well satisfied with the results of the traffic obtained on its Tynemouth lines, and while the traffics on the District and Metropolitan Railways are now beginning to show steady improvement as the result of electrification, the actual balance-sheet of expenses and receipts has not been made public. A number of preliminary figures regarding the New York Central lines have been published, but they were hardly complete enough and the result of too recent work to be of much value. While as regards engineering experience there is a free interchange of ideas between the different makers and the various engineers concerned, there is less of this as regards traffic receipts.

It is to be hoped that ere long it will be possible for those responsible for the management of lines which are being electrically worked in this country to make public some of the results they have obtained for the benefit of those who are still considering the question.

\section{THE TELEGRAPHIC TRANSMISSION OF WRITING.}

THE advent of the telewriter should obviate the mistakes and misunderstandings which so commonly occur in business messages transmitted by telephone, and should save the repetition work now necessary owing to messages having to be confirmed by letter.

The telewriter consists of a transmitter and receiver. The message to be sent is written in pencil on a roll of paper attached to the transmitter, and is exactly reproduced in pen and ink on the distant receiver. The pencil at the transmitter is fixed at the junction of two jointed rods, which are connected to each of two shafts, and communicate a rotary movement to them. These shafts in turn move contact pieces, which cause a variation of voltage in two electrical circuits. These circuits control two moving coils suspended in an electromagnetic field in the receiver, and the jointed rods connected to these coils actuate the pen which reproduces the writing-or message - on a roll of paper at the receiver.

Thus any motion of the pencil at the transmitter is resolved into two component movements, which cause a variation of the positions of the moving coils at the receiver. These coils, actuating the two levers to which the receiving pen is attached, reproduce the motions of the pencil at the transmitter.

When the paper available for writing on at the transmitter has been used up, it is fed forward mechanically by pulling a lever, which at the same time causes a

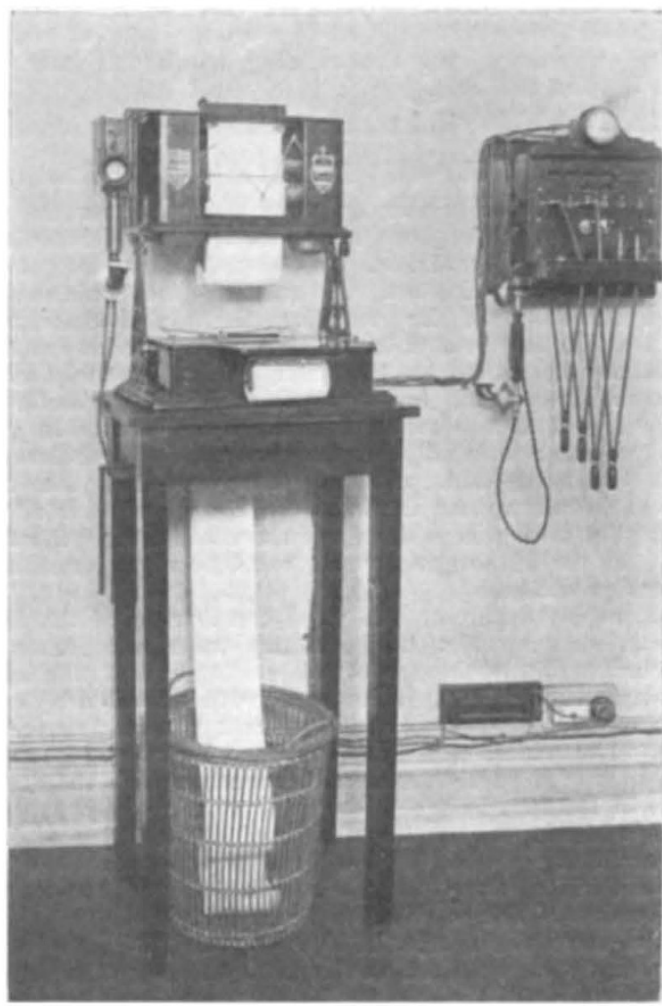

Telewrier Transmitt ${ }^{\circ}$ and Receiver arrang ed with Teleph one and Departmental Exchange.

current to be sent through both lines and operates a relay which actuates the paper in the receiver proportionately.

Before starting to send a message, a button is pressed on the transmitter, and this automatically ensures the lever at the receiving end being in the proper position for the instrument to receive a message. The receiving pen-before contact is made by the pencil on the transmitterreposes in an ink-well, and this ensures that plenty of ink is always obtainable. The telewriter is also fitted with a telephone, and communication can be held by either method over the same lines, but not simultaneously.

An advantage of the telewriter over the telephone is that, should the person rung up be out, the message can be written and will await his return. No operator is necessary to receive the messages, and so long as the rolt of paper in the receiver lasts, so long can messages be received.

The ordinary telephone wires are all that is necessary for the operation of the telewriter, the power being

NO. 2050, VOL. 79] 
obtained from either batteries or the central station supply. Both direct current and alternating currents can be used, but in the latter case a rectifier must be placed in circuit.

Messages can be sent to practically any number of telewriters from one transmitter, thus assuring the same message being received simultaneously on the various receivers.

The Postmaster-General has granted a licence for twentyone years to the Telewriter Syndicate, and after I9II, when the National Telephone Company's licence expires, the Telewriter Syndicate will operate its own system and establish telewriter exchanges, paying royalties for the same. These lines will be independent of the Post Office telephones, but will be leased from the Post Office, and tclephonic communication in addition is to be a sine qua non on all these lines.

At present the telewriter is established chiefly on private lines, and is working satisfactorily in many large warehouses, stores, and offices, but messages and sketches have been successfully sent from London to Manchester over the Post Office telephone trunk lines, which were used, by permission, for the experiment. Arrangements and special instruments are now being made with the view of sending similar messages over the existing trunk telephone line from London to Paris.

\section{SOME ENTOMOLOGICAL PAPERS.}

$A$ MONG recent papers on entomology in serials with which we have been favoured, special reference may be made to one by Mr. P. H. Calvert on the dragon-flies (Odonata) of Mexico and Central America, published in the Proceedings of the Academy of Natural Sciences of Philadelphia for October last. This paper, which is mainly based on the article by the same author in the Biologia Centrali Americana, forms an important contribution to the study of insect-faunas generally, and treats in great detail of the relationships of the group under consideration. It is assumed-and probably correctly-that the adult insects do not wander far from the haunts of their aquatic larvæ, but until this is definitely ascertained the generalisations, as the author points out, must be regarded as more or less provisional.

To the sixth part of vol. v. of the Annals of the South African Museum Mr. L. Peringuey contributes a seventh instalment of his account of the coleopterous fauna of the country, dealing in this instance with considerably more than one hundred species and several genera described as new. The paper, which is illustrated by two monochrome plates, is of a purely taxonomic character, with the descrip-
tions in Latin.

An addition to our knowledge of the aphides of Japan is furnished by Mr. G. Okajima in vol. viii., No. I, of the Bulletin of the College of Agriculture of the Imperial University of Tokio. This paper is devoted to the description of three new species of Trichosiphum, a genus founded so recently as 1906 for the reception of another Japanese representative of the group. To the same issue this author contributes a more generally interesting paper, namely, one on the structure of the aphid antennæ. These antennæ are composed of not more than six joints, of which the third and later ones (especially the third) usually bear sensory pits. For their distal portion the name "flagellum" is adopted. It is found that, as regards minor characters, the antennæ present specific differences which harmonise well with the various groups into which the family has been divided.

In a third paper in the serial last cited Mr. T. Miyake gives a list of Japanese Panerpidæ, together with descriptions of ten new species of the type-genus, all of which are illustrated in an accompanying plate. All the new species, which display the general type of colouring characteristic of these elegant insects, agree with the other Japanese members of the group in regard to a peculiarity in one part of the wing-venation.

Under the title of Indian Forest Memoirs, the Government of India has commenced the issue of a new quarto serial, intended for the publication of the more important results of the investigations of the Imperial Forest Research Institute. The publication of Indian Forest hecords is to be continued for minor papers, and the two serials are to constitute the Forest Zoology Series. The first part of the Memoirs is devoted to an account, by Mr. E. P. Stebbing, of some undescribed Scolytidæ of economic importance from the Indian region. Until recently, very little was known with regard to the Indian representatives of this group of bark-boring beetles, and scarcely anything of their life-histories and food-plants. It is now ascertained that the Scolytidæ are of very considerable importance to the Indian forester, this being specially the case as regards the great coniferous forests of the Himalaya. Other species, referable to the genus Sphærotrypes, are, however, detrimental to the sal-forests and other broad-leaved timber-trees. In the present memoir Mr. Stebbing describes three new species of the last-named genus, five of Polygraphus, and two of Dryocetes. Among the species of Sphærotrypes, one, S. assamensis, infests the sal-timber of Assam and eastern Bengal, and a second, $S$. quercyi, the oaks of Kumaun.

The Angolese tiger-beetles of the subfamily Cicindelinæ form the subject of an article by Messrs. F. Creighton Wellman and W. Horn in the Proceedings of the Academy of Natural Sciences of Philadelphia for November, 1908. Angola, it appears, is divisible into three distinct physical regions, namely, lowlands, mountainous slopes, and high plateau, the climate of the second of these being cooler and moister than that of the first, although not to the same degree as the third. Each of these areas has its own special tiger-beetle fauna, that of the middle zone possessing the largest number of species.

In this place reference may be made to investigations undertaken in Cornell University by Mr. B. H. Guilbeau, of which the results are published in the American Naturalist for December, 1908, as to the mode in which the "cuckoo-spit insects" (Cercopidæ) secrete the foam in which they are enveloped. By cleansing the nymphs from the investing froth, it has been ascertained that the fluid issues from the anal aperture, and is converted into froth by periodical removals of the tip of the abdomen, which is re-introduced holding each time a bubble of air. Viscosity is imparted to the fluid by the secretion of the glands of Batelli.

In conclusion, brief mention may be made of an.interesting article, by $\mathrm{Mr}$. A. H. Swinton, on the vocal and instrumental music of insects, the first instalment of which appears in the January number of the Zoologist.

\section{THE CHARGES ON IONS. ${ }^{1}$}

THE ratio of the charges of ions in liquids to those produced by various methods in gases is a factor that enters into many investigations connected with molecular theories, so that it is of importance that the connection between these charges should be investigated by some accurate method.

The simple relations that hold between the charges of ions in liquids can be easily deduced from the theory of electrolytic conduction. It follows immediately from determinations of the electrochemical equivalents that the charge on any ion in a liquid is either equal to that on a hydrogen atom or an exact multiple of it. No method has been devised for determining this charge directly, but the value of $n \times e$, the product of the number of molecules in a cubic centimetre of a gas at standard pressure and temperature $\left(15^{\circ} \mathrm{C}\right.$.) and the charge $e$ expressed in electrostatic unts, is accurately known, and is approximately $1.23 \times 10^{10}$.

In gases it is possible to obtain a rough estimate of the charge on an ion. The method of determining the charge, which requires a cloud to be formed in the gas, was given by the present writer (Proc. Camb. Phil. Soc. vol. ix., part v., February, 1897), and was first applied to the ions in newly prepared gases. The same principle was subsequently used by Sir J. J. Thomson and Prof. H. A. Wilson in determining the charges on ions produced by Röntgen rays, ultra-violet light, and radio-active substances (J. J. Thomson, "Conduction of Electricity through Gases "). The numbers obtained for $e$ in electrostatic units range from $3 \times 10^{-10}$ to $9 \times 10^{-10}$, but an

1 Based upon papers by Prof. J. S. Townsend, F.R.S., and Mr. Haselfoot, communicated to the Royal Society January and November, 1908.

No. 2050, VOL. 79] 